\title{
Materials Science and Engineering - Some Aspects in Central and Eastern European (CEE) Countries
}

\author{
József GYULAI
}

Hungarian Academy of Sciences, Resource Centre for Energy Research, Institute of Technical Physics and Materials Science, MFA, Budapest, Hungary, gyulai.jozsef@energia.mta.hu

\begin{abstract}
This introductory paper summarizes the characteristics of how "Science" and "Engineering" differ from each other, forming the interdisciplinary topic of Materials Science and Engineering (MS\&E). It will be shown how microelectronics has developed from modern materials science, causing a change in paradigm, and how microelectronics has become the "mother" science of informatics, changing life on Earth. To prove the importance of materials, a table is shown summarizing how modern MS\&E forms the basis of practically all industries. The situation and development state of MS\&E in CEE countries - despite different levels of industrialization - have some characteristics in common, and the way to development might also have techniques in common.

We will also mention the knowledge base that CEE countries possessed during the period of political change, and the likely future that an elderly scientist foresees for the region with the help of young ambitious scientists.
\end{abstract}

Keywords: material science, engineering, microelectronics, interdisciplinary material science.

\section{Introduction}

This paper is devoted to young engineering students with the aim of strengthening their devotion to a future career. Before we turn to the topic of this paper, a short chapter is included to draw attention to how the 21st century places a heavy onus on the shoulders of these future engineers. The global success of engineering is a key factor in keeping our planet habitable. A safe solution seems to be the so-called "Circular economy", which states that all production and consumption processes are part of a closed cycle of material flow requiring minimum energy. It is believed that there is no more important a task in science today than tstudy if, and if so how ten billion people can live on Earth without catastrophically destroying the interdependent network of living creatures. This is the message that must be clarified to young engineers.

To find the answer, a few words are devoted to the often confused relationship of "science" to "engineering”? Scientists, especially experimen- talists, seek and find new phenomena and try to find explanations for experimentally observed facts. In this often "curiosity driven” process, models are defined based on mathematics, information technology, etc. the level of which, of course, is dependent on the available knowledge at the time. The applications of their work in the future are not immediately foreseen. Thus, when planning an experiment, numerous influencing factors must be neglected in order to arrive at a solution that best fits the state of theoretical development at that time. Once basic laws and facts are accepted, future talented "engineer-scientists" look at and treat basic laws of physics, chemistry etc. as "tools" which can be used to form materials into structures - products with expected, or rather with predetermined properties. Therefore, the engineer-scientist has to account for as many as possible at his time of these by constraint parameters in order to arrive at a better defined solution, a solution which enables the building of reliable future products. If this definition of engineering science is accepted, then a second 
step follows in which a collective of engineers will define and optimize parameters such as temperature, time duration, pressure, chemical doping, etc., under which these law-based "tools" should act and change properties of the material in question. These conditions, rules and prescriptions will convert 'experiment' into a 'product', whose final acceptance will be evident in the economy.

\section{Materials science and engineering (MS\&E), in general}

Modern MS@E is the daughter of informatics. It does not imply that the earlier forms of this science were not useful - think e.g. of swords of Damascus, or the dawn of metallurgy described in the book of Agricola, the Dé rē metallica (1556) [1]. But, quantification of metallurgical processes by the use of informatics, in a very broad sense, has caused a fundamental paradigm change. Today, the understanding of processes, often on an atomic scale, allows mankind to improve technology and to produce products on an industrial scale.

It may not be an exaggeration that microelectronics technology was and still is the leading field of science that drives automation, robotics, system control and quality management forward, by demanding new and better solutions. A summary of a few examples follow relating to materials science and the demands of transistor technology.

In this example, the goal is - as the drawing from Figure 1 shows - to control the flight of charge carriers within a so-called space charge layer, from the source (S) region to the drain (D), (in the rear of Figure 1 under a SiO2-insulated metal layer on top, called the gate $(G)$ ). Carrier A flies freely: "ballistically accelerated", carrier B's track interacts with potential wells of deliberately embedded ions to control operation voltage. This interaction, however, "heats" the crystal, and this heat must be conducted away - a serious problem

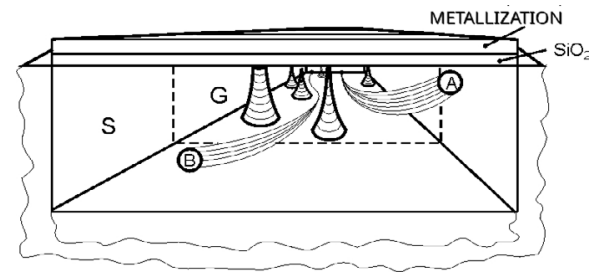

Figure 1. Visualized tracks (ballistic, A, and scattered, B) of charge carriers from Source (S) to Drain (D) in the so-called space charge layer of a Metal-Oxide-Semiconductor, MOS, transistor if, for example. millions of transistors are connected to form, e.g., a logic circuit.

"Exponential" means that the number of elements doubles yearly. Moore was modest enough to think that this unprecedented development would stay with us, say, till end of the seventies. It turned out that his modesty was an understatement: we are still seeing the law being fulfilled even today, though with some additional corrections, e.g., the exact 2D-version of an integrated circuit (IC) would not allow further miniaturization, structures must leap out into a $3^{\text {rd }}$ dimension. Nature, however, has assisted mankind by means of the so-called "Dennard scaledown": if all dimensions of a transistor are multiplied by a number smaller than one, it is only the heat emission that will change and the electrical properties will remain the same. Today, industry is at " $12 \mathrm{~nm}$ technology”, i.e. the smallest features are around $12 \mathrm{~nm}$.

With this in mind, an overview can be given of what the effect of this miniaturization is upon precision of production technology, when individual transistors are smaller than a virus.

1. Defect free crystals. It is the element silicon which holds the size-record for growing a defect free single crystal, using the Czochralski-growing technology. A few hundred kN crystal is sliced into $300 \mathrm{~mm}$ diameter crystallographically oriented wafers of about 700 micron thickness, ground and polished to a few tenths of a nm root-mean-square (r.m.s.) roughness, more aptly called "smoothness". Finally, it is cleaned beyond 'chemical' cleanliness, packaged and delivered to the semiconductor foundry. The maximum number of surface dislocations is below $1 / 10 \mathrm{~cm}^{2}$.

2. Dielectric ( $\mathrm{SiO}_{2}$, or high-dielectric constant) layer growth. Scaling down requires thinner and thinner insulation between the metal gate and space charge layer in the silicon. Currently down to a few nm, i.e., to a thickness of few elementary cells. This thickness can grow in reduced $\mathrm{O}_{2}$-pressure in seconds, homogeneously over the $300 \mathrm{~mm}$ wafer. Steps, even single atomic steps at the $\mathrm{Si}_{\mathrm{SiO}_{2}}$ interface, are not allowed more than at every $10,000^{\text {th }}$ atom (as atomic steps involve inherently dangling chemical bonds, which can act as traps for the carriers).

3. Photolithography. To form structures with some $10 \mathrm{~nm}$ size requires around $100 \mathrm{~nm}$ wavelength illumination in lithography. To arrive at faultless structures of a tenth of this wavel- 
ength, all diffraction must be avoided, and this requires extremely high quality optics.

4. All of the above need to be adhered to in order to perform at nearly $100 \%$ output...

It is believed that these requirements convince the Reader of the uniqueness of this industry. To add more, as sizes shrink into the nanometer range, the latest version of microelectronics is called "nanoelectronics", where other binary quantities, like spins, act as the carrier of digital information ("spintronics"). Then, we arrive at the next stage, quantum computing, which may reach industrial level in the coming decades. However, a decade or longer time lag is usual between successful lab experiments and mass production.

No wonder that until turn of the millennium, microelectronics merged into and fertilized all branches of industry, both physics and chemistry based ones, and we witness its slow penetration into the bioindustry. Usually the software basis of regulation first leads penetration, is followed by automatization and, finally, robotization of the hardware. Later in this paper, a summary of this fertilizing penetration of MS\&E will be given.

\section{Forms of MS\&E}

Two forms of MS\&E are often distinguished. One is the so-called "top down" process, the other is the "bottom up" process. The first form is the ancient idea, as it represents, e.g., the stone age technique of how sharp obsidian tools, flints were made. Analogous techniques prevail, say, in the lathe turning of metals. Here, trillions of bonds go broken resulting in heating, representing energy loss. This can be somewhat diminished using form casting. Better forms are the bottom up techniques, the pinnacle of which is plant life [3]. An early lecture of R. Feynman is often quoted as a prophesy of nanoscience or nanotechnology [4]. Today ground-breaking nanotechnology processes use predominantly bottom-up-type processing, like nanoelectronics.

\section{Materials engineering and branches of industry}

MS\&E is a horizontal science: practically no product of human activity is imaginable that doesn't involve some kind of material. It is normal that all products have a demand on a specific raw or starting material. The Table 1 summarizes today's leading research in different materials and their importance in different industries. The re- ader may find missing data, comments, but the complexity of this tutorial table must surely be convincing.

\section{Conclusions for CEE young students, engineers}

The structure of industry in CEE countries at the onset of political changes was unique. Being earlier members of an alliance, their industries were specifically developed in the interests of the military needs of the cold war, although with some consideration of local specialities. The main direction was in heavy industry (steel, oil, etc.), thus, materials science was more like the Russian-Soviet "Materialovedenie", or the GDR "Werkstoff-Forschung" resembling more the historically important and valuable at the time of the "Old Metallurgist”. The reason? As informatics was considered by the Soviet ideology as a "capitalist pseudoscience”, modern MS\&E work could start to develop ion CEEs only with the advent of fundamental political changes, the levying of embargo, in the nineties. This was not an easy task, as e.g., even patent matters were not considered earlier at all and a clearing-up took a lot of effort, foreign capital influx, factory shutdowns, etc. ${ }^{1}$ We had a generation of engineers, who were prevented from travelling, yet with huge personal experience, albeit with a kind of amateurism as seen from the outside. However, they were trained in a special skill: the ability to solve problems individually, by instinct. The author's experience in the liberated Hungary was not at all negative, though his country enjoyed a certain and relative freedom where earlier international practice was concerned.

The new freedom for the young ones in the nineties was difficult to live with. Scientific, industrial partnership is a matter of trust, of friendship. To build this up is not just a web partner search, but takes time and personal effort, friendly "get-togethers" at conferences, etc. Slowly, however, we are seeing results. Some of them are pseudo-negative, when one considers the probably never-to-return intellectual power but clever science and good industrial politics can improve this. The author's personal exposure to the establishing of Intel in the US (1969 and thereafter) as part of his Caltech post doctorate, and his involvement in the R\&D of Intel's mother company, Fairchild Semiconduc-

1 The author's eyes were opened in the eighties, when working as a research associate at Faculty of MS\&E of Cornell University (NY). 


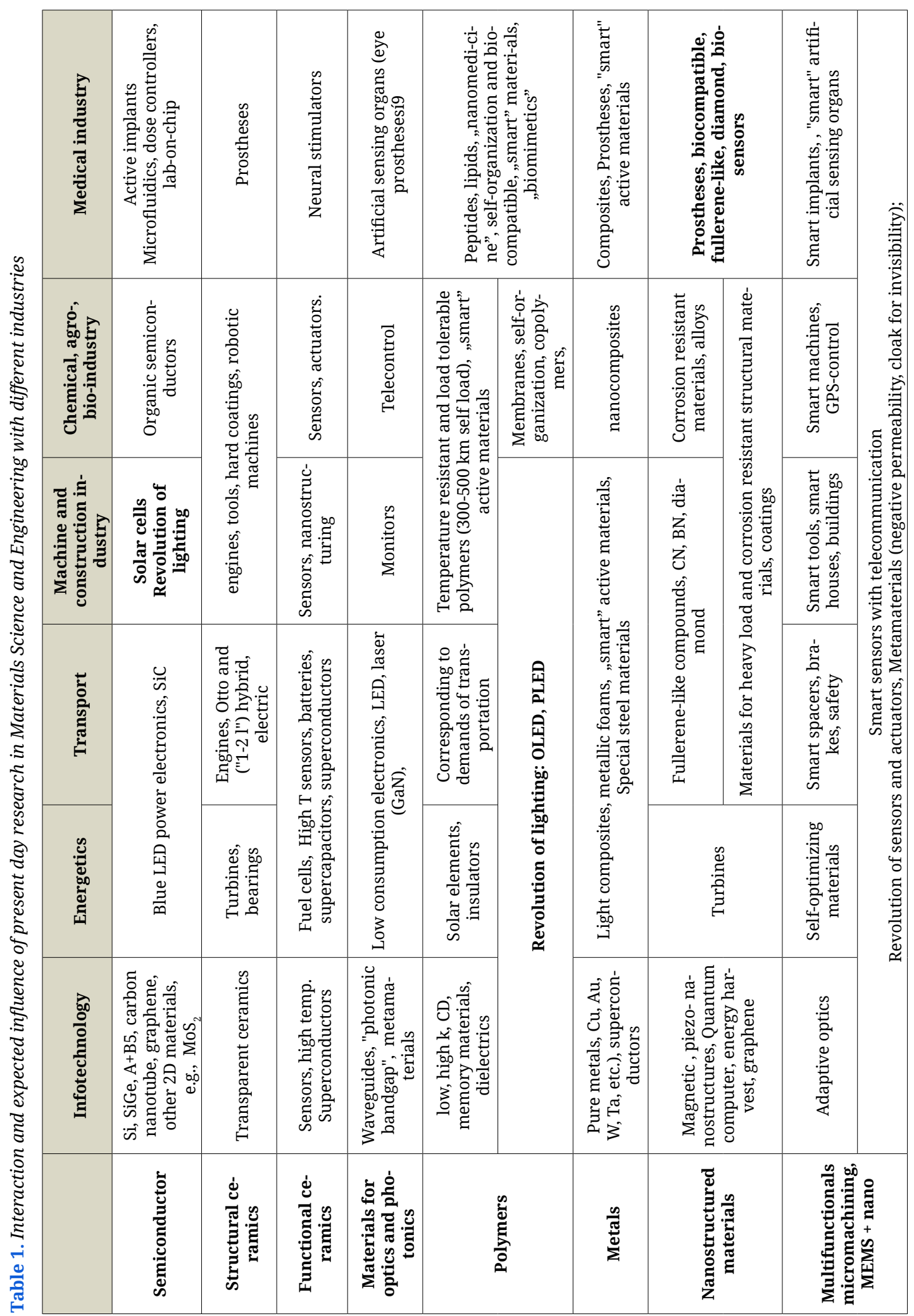


tors, proves that being part of a big company, clever engineers may pick up enough knowledge to start their own company. Maybe first as a component deliverer. This is what I maintain as a hope for young engineers in CEE countries. [5] [6]

\section{References}

[1] Agricola G.: De re metallica. Basel, 1556. http://www.gutenberg.org/files/38015/38015h/38015-h.htm

[2] Moore G.: Cramming more components onto integrated circuits. Electronics, 38/8. (1965).

http://archive.computerhistory.org/resources/access/text/2017/03/102770822-05-01-acc.pdf
[3] Drexler E. K.: Engines of creation: The coming era of nanotechnology. Anchor Books, New-York, 1986.

http://e-drexler.com/p/06/00/EOC_Cover.html

[4] Feynman R. P.: There's plenty of room at the bottom. Előadás, American Physical Society, Caltech, Pasadena, 1959. december 29.

Átírata: http://www.zyvex.com/nanotech/feynman.html (letöltve: 2018. május 15.)

[5] Gyulai J.: Materials science and its importance in middle and central Europe. In: Physics and industrial development. Bridging the gap. (Chandrasekhar S. (szerk.)), Wiley Eastern Ltd., New Delhi, 1995. 227-232.

[6] Gyulai J.: Jedlik vagy Siemens? Új Magyarország, 3. (1993. június 26.). 